\title{
The Pleiotropic Effects of Sodium-Glucose Cotransporter-2 Inhibitors: Beyond the Glycemic Benefit
}

\author{
Dhiren K. Patel · Jodi Strong
}

Received: July 3, 2019 / Published online: August 27, 2019

(C) The Author(s) 2019

\section{ABSTRACT}

Type 2 diabetes (T2D) is associated with an increased risk of macro- and microvascular complications, including cardiovascular disease (CVD), heart failure (HF), and chronic kidney disease (CKD). Of the currently available glucose-lowering therapies, sodium-glucose cotransporter-2 inhibitors (SGLT-2is) are the only class to target the pathophysiologic increase in renal glucose reabsorption in patients with T2D. In CV outcomes trials of SGLT-2is in patients with T2D and established CVD or varying levels of CV risk, empagliflozin, canagliflozin, and dapagliflozin were associated with significant improvements in the risk of composite $\mathrm{CV}$ and renal outcomes compared with placebo that extended beyond their glycemic effects. Real-world observational studies have also reported improvements in $\mathrm{CV}$ outcomes with SGLT-2is compared with other glucose-lowering therapy in routine clinical

Enhanced Digital Features To view enhanced digital features for this article go to https://doi.org/10.6084/ m9.figshare.9638816.

D. K. Patel $(\bowtie)$

VA Boston Healthcare System, Boston,

Massachusetts 02130, USA

e-mail: dhiren.patel@va.gov

J. Strong

Ascension Medical Group, 824 Illinois Ave, Stevens

Point, Wisconsin 54481, USA practice. This review describes the pleiotropic effects of SGLT-2is and discusses the potential mechanisms for these effects as well as how they potentially provide benefits beyond glycemic control in patients with T2D. These favorable nonglycemic effects indicate that SGLT-2is may be of particular benefit in patients with diabetic complications, such as CVD, HF, or CKD. Ongoing large randomized trials in specific patient populations, including those with CVD, HF, or CKD (with or without T2D), may help to confirm the benefits of SGLT-2is in these patients and further elucidate the potential mechanisms of their pleiotropic effects.

Funding: AstraZeneca.

Keywords: Cardiovascular disease; Chronic kidney disease; Pleiotropic effects; Sodiumglucose cotransporter-2 inhibitors; Type 2 diabetes

\section{INTRODUCTION}

Type 2 diabetes (T2D) is a progressive disease characterized by impaired insulin secretion and/or increasing insulin resistance, resulting in chronic hyperglycemia [1]. In patients with T2D, chronic hyperglycemia often leads to macrovascular (cardiovascular disease [CVD]) and microvascular (nephropathy, retinopathy, and neuropathy) complications, which are associated with an increased risk of morbidity 
and mortality [2]. In addition, T2D is associated with worsened health-related quality of life and increased healthcare costs [3-6].

Current glucose-lowering therapy options target one or more of the eight metabolic and endocrine defects (the ominous octet) underlying the pathophysiology of T2D (Fig. 1) [7, 8]. These defects include decreased pancreatic insulin secretion, decreased incretin effect, increased glucagon secretion, increased hepatic glucose production, decreased glucose uptake, increased lipolysis, increased renal glucose reabsorption, and neurotransmitter dysfunction $[7,8]$.

The kidneys perform an essential role in glucose homeostasis, with renal glucose reabsorption predominantly ( $\sim 80 \%-90 \%)$ mediated by sodium-glucose cotransporter-2 (SGLT-2) in the proximal tubule $[9,10]$. In healthy individuals without T2D, the maximum renal glucose reabsorptive capacity exceeds the amount of glucose filtered at the glomerulus, and all of the filtered glucose is reabsorbed into the plasma circulation to maintain normal plasma glucose levels [9]. In patients with T2D, increased SGLT-2 expression and activity in the proximal tubule lead to abnormally high renal glucose reabsorption, which contributes to persistent hyperglycemia (Fig. 2) [10-12].

SGLT-2 inhibitors (SGLT-2is) reduce plasma glucose levels in patients with T2D by decreasing the renal glucose reabsorptive capacity in the proximal tubule by up to $50 \%$ of the filtered glucose load, thereby promoting urinary excretion of glucose (Fig. 2) [12, 13]. In contrast to other classes of glucose-lowering therapy, SGLT2is are the only class to specifically target the

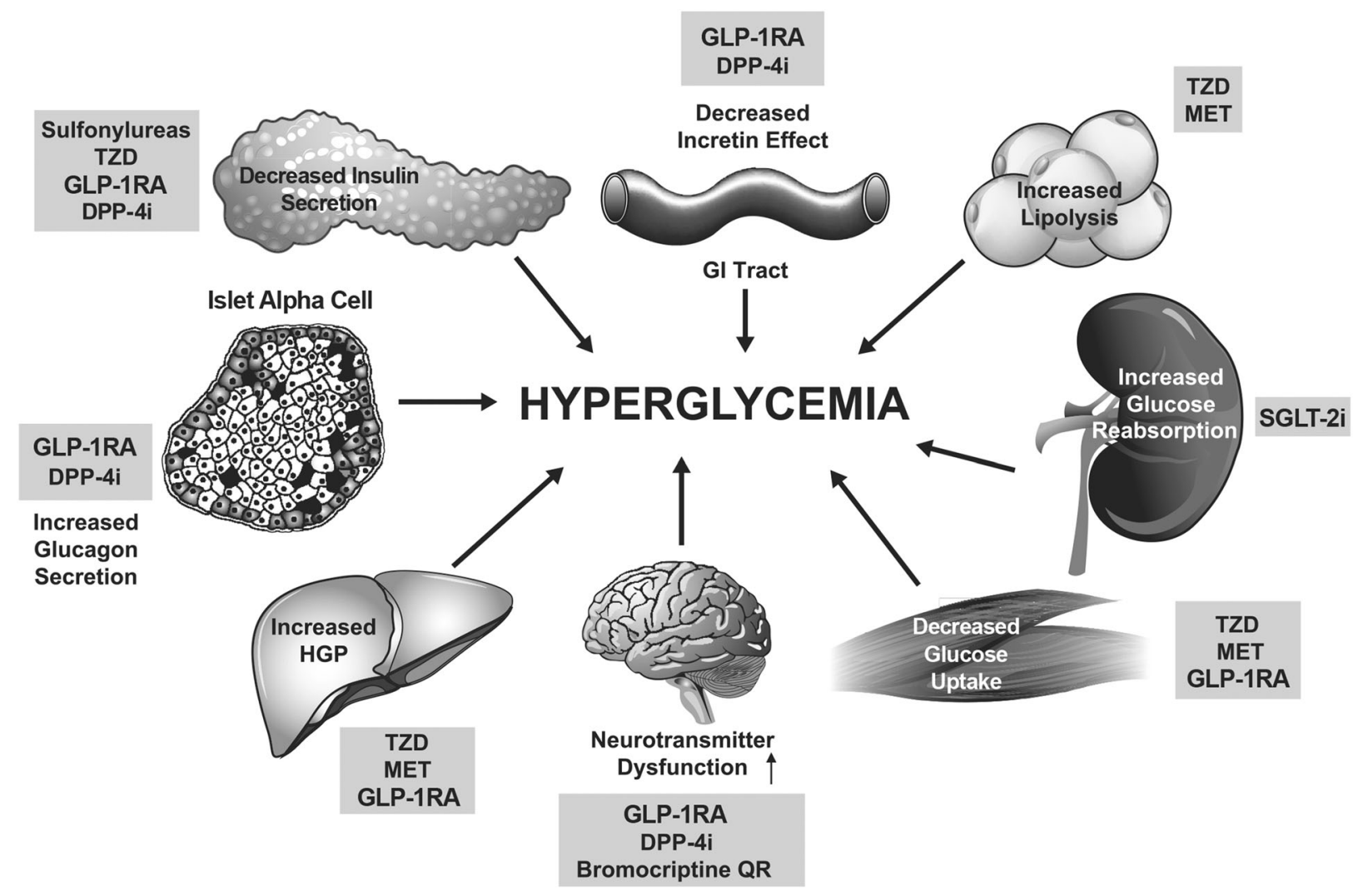

Fig. 1 The ominous octet. Mechanisms and site of action of glucose-lowering medications based on pathophysiologic disturbances in type 2 diabetes [7]. Reproduced with permission from Thrasher et al. 2017 [8]. DPP-4i dipeptidyl peptidase-4 inhibitor, $G I$ gastrointestinal,
GLP-1RA glucagon-like peptide-1 receptor agonist, HGP hepatic glucose production, $M E T$ metformin, $Q R$ quick release, $S G L T-2 i$ sodium-glucose cotransporter-2 inhibitor, $T Z D$ thiazolidinedione 


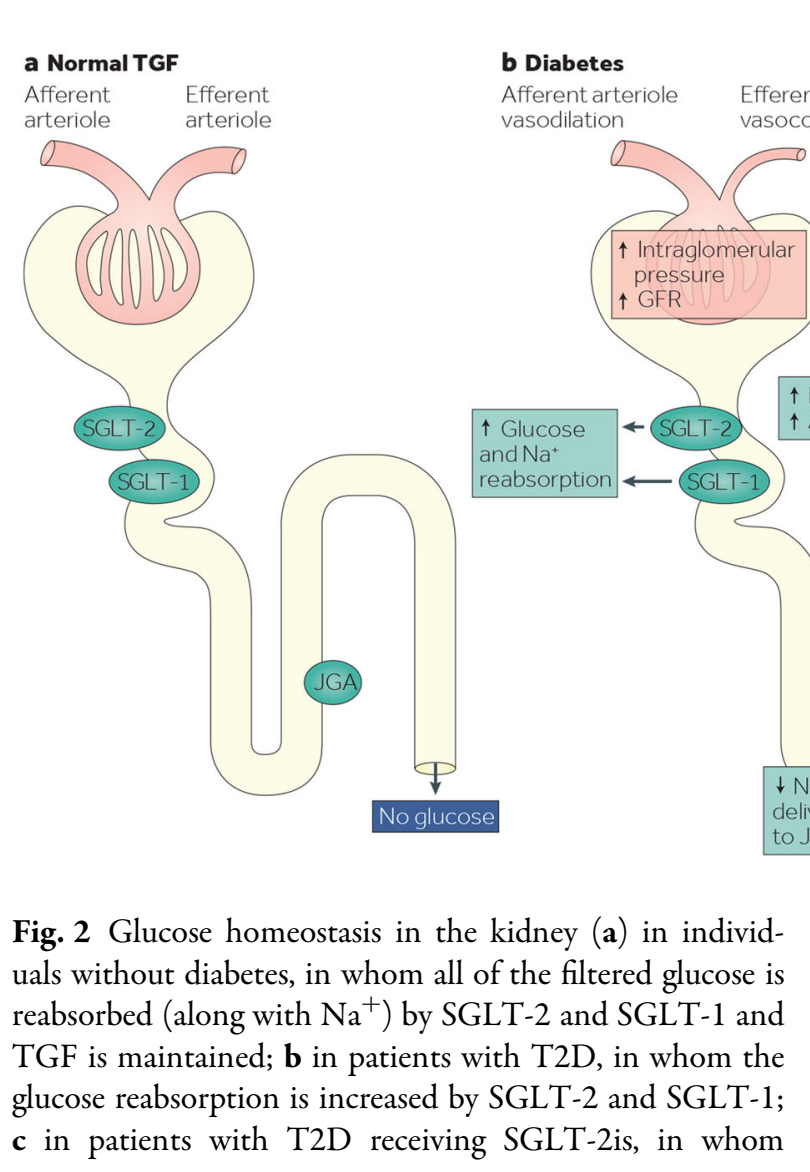

renal pathophysiologic defect of T2D [8]. Because this mechanism of action is independent of insulin and does not affect the metabolic regulation of glucose, SGLT-2is are associated with a low risk of hypoglycemia $[13,14]$. SGLT-2is also remain effective in the presence of progressive loss of beta-cell function or insulin resistance and may act synergistically when used in combination with other glucoselowering therapies [14].

In CV outcomes trials (CVOTs) of SGLT-2is, reductions in the risk of various composite $\mathrm{CV}$ and renal end points compared with placebo were observed with empagliflozin in patients with T2D and established CVD [15, 16] and with canagliflozin [17] and dapagliflozin [18] in patients with T2D and established CVD or varying levels of $\mathrm{CV}$ risk. These findings led to revisions in the treatment strategy for T2D, with clinical associations recommending the inclusion of SGLT-2is in patients with established reabsorption of glucose and $\mathrm{Na}^{+}$is decreased and urinary glucose excretion is increased. Reproduced with permission from DeFronzo et al. 2017 [12]. GFR glomerular filtration rate, $J G A$ juxtaglomerular apparatus, $\mathrm{Na}^{+}$sodium, $S G L T$ sodium-glucose cotransporter, SGLT-2is SGLT-2 inhibitors, $T 2 D$ type 2 diabetes, $T G F$ tubuloglomerular feedback

CVD, heart failure (HF), or chronic kidney disease (CKD) [19-21].

This review describes the pleiotropic effects of SGLT-2is and discusses the potential mechanisms for these effects as well as how they may provide additional benefits beyond glycemic control in patients with T2D.

\section{SEARCH STRATEGY}

A literature search of PubMed was conducted on February 13, 2019, for English-language publications using the following search terms: (SGLT2 inhibitors OR SGLT-2 inhibitors OR SGLT-2is OR SGLT2is OR sodium-glucose cotransporter 2 inhibitors OR sodium-glucose cotransporter-2 inhibitors OR empagliflozin OR canagliflozin OR dapagliflozin OR ertugliflozin) AND (type 2 diabetes mellitus OR type 2 diabetes OR T2D OR non-insulin dependent diabetes) AND (nonglycemic effects OR nonglycaemic effects OR non-glycemic effects 
OR non-glycaemic effects OR pleiotropic effects). Additional literature was identified by review of bibliographies from the reference data set. This article is based on previously conducted studies and does not contain any studies with human participants or animals performed by any of the authors.

\section{CARDIOVASCULAR EFFECTS OF SGLT-2 INHIBITORS}

\section{Randomized Clinical Trials}

In clinical studies of patients with T2D, SGLT2is provided effective reductions in glycated hemoglobin and fasting blood glucose and were associated with improvements in several CV risk factors, including decreases in body weight, blood pressure (BP), waist circumference, and triglycerides, and an increase in high-density lipoprotein (HDL) cholesterol [22-24]. However, slight increases in low-density lipoprotein (LDL) cholesterol levels have also been observed with SGLT-2is [15, 17].

In CVOTs of empagliflozin (EMPA-REG OUTCOME) and canagliflozin (CANVAS), the risk of the three-point major adverse $\mathrm{CV}$ event composite outcome [3-point MACE; defined as $\mathrm{CV}$ death, nonfatal myocardial infarction (MI), or nonfatal stroke] was significantly reduced by $14 \%$ versus placebo in patients with T2D and established CVD in EMPA-REG OUTCOME [15] or in patients with T2D and established CVD or multiple CVD risk factors in CANVAS [17] (Table 1). These trials also demonstrated a significant reduction in the risk of hospitalization for $\mathrm{HF}$ with empagliflozin (by 35\%) and with canagliflozin (by 33\%) versus placebo $[15,17,25,26]$.

Although absolute numbers of patients with established CVD were similar across the three CVOTs, the DECLARE-TIMI 58 study of dapagliflozin included a larger proportion of patients with multiple CV risk factors without established CVD $(\sim 60 \%)$ and a smaller proportion of patients with established CVD than the other two SGLT-2i trials ( 40\%; vs. $>99 \%$ in EMPAREG OUTCOME and $\sim 66 \%$ in CANVAS $[15,17])$, representing a population at an earlier stage of CVD risk $[18,27]$. In DECLARE-TIMI 58, dapagliflozin showed noninferiority to placebo in the risk of three-point MACE [18], with a greater risk reduction in patients with a prior MI versus those without (16\% vs. $0 \%)$ [28], and dapagliflozin significantly reduced the risk of the composite outcome of CV death or hospitalization for HF by $17 \%$ versus placebo (Table 1), primarily resulting from a lower rate of hospitalization for HF [18]. A subanalysis showed that dapagliflozin reduced the risk of $\mathrm{CV}$ death or hospitalization for HF to a greater extent in patients with a history of HF with reduced ejection fraction (HFrEF) than in those without HFrEF, defined as HF without known reduced $\mathrm{EF}$ or without history of $\mathrm{HF}$ (38\% vs. $12 \%)$ [29].

A meta-analysis of data from these three CVOTs indicated that SGLT-2is reduced the overall risk of three-point MACE by $11 \%$ compared with placebo (Fig. 3) [30, 31]. This reduction in the risk of MACE was observed only in patients with atherosclerotic CVD, whereas patients with multiple CVD risk factors showed no treatment effect [30]. In this metaanalysis, SGLT-2is reduced the overall risk of the composite outcome of $\mathrm{CV}$ death or hospitalization for HF by $23 \%$ and hospitalization for HF by $31 \%$ compared with placebo. The hospitalization for HF outcome was similar among patients with atherosclerotic CVD and those with multiple CVD risk factors, with $\sim 30 \%$ risk reduction in both subgroups.

\section{Real-World Observational Studies}

Real-world studies have also indicated that SGLT-2is have beneficial CV effects in routine clinical practice that extend beyond those seen with other glucose-lowering therapy in patients with T2D (Table 2). The multinational CVDREAL study showed improvements in CV outcomes, including reductions in the risk of hospitalization for HF (by 39\%) and in the risk of hospitalization for HF or death (by 46\%), with newly initiated SGLT-2i therapy (empagliflozin, canagliflozin, or dapagliflozin) compared with other glucose-lowering therapy (Table 2) [32-34]. This lower risk of hospitalization for HF 
Table 1 Summary of pleiotropic effects of SGLT-2is in randomized, placebo-controlled cardiovascular outcomes trials

EMPA-REG

CANVAS $[17,59]$

DECLARE-TIMI $58[18,60,61]$

OUTCOME

$[15,16]$

Study design

$\begin{array}{lll}\begin{array}{l}\text { Patient } \\ \text { population }\end{array} & \begin{array}{c}\text { Age } \geq 18 \text { years with } \\ \text { T2D and } \\ \text { established CVD } \\ (n=7020)\end{array} & \begin{array}{c}\text { Age } \geq 30 \text { years with T2D and } \\ \text { established CVD or age } \\ \geq 50 \text { years with T2D and } \geq 2 \\ \text { CVD risk factors } \\ (n=10,142)\end{array} \\ & & \\ \text { Treatment } & \text { Empagliflozin }(10 \text { or } & \text { Canagliflozin }(100 \text { or } 300 \mathrm{mg}) \text { or } \\ & 25 \mathrm{mg}) \text { or matched } & \text { matched PBO once daily } \\ & \text { PBO once daily } & \\ \text { Primary end } & \text { Composite of CV } & \text { Composite of CV death, nonfatal } \\ \text { point } & \text { death, nonfatal } & \text { MI, or nonfatal stroke } \\ & \text { MI, or nonfatal } & \\ & \text { stroke } & \end{array}$

Age $\geq 40$ years with $\mathrm{T} 2 \mathrm{D}$ and established CVD or age $\geq 55$ years (males) or $\geq 60$ years (females) with $\mathrm{T} 2 \mathrm{D}$ and $\geq 1 \mathrm{CVD}$ risk factor (hypertension, dyslipidemia, or current smoker)

$(n=17,160)$

Dapagliflozin $10 \mathrm{mg}$ or matched PBO once daily

Safety

CV death, MI, or ischemic stroke

Efficacy

(1) CV death, MI, or ischemic stroke

(2) CV death or hospitalization for HF

CV outcomes, SGLT-2i vs. PBO, rate per 1000 PY (HR [95\% CI])

\begin{tabular}{|c|c|c|c|}
\hline \multirow{5}{*}{$\begin{array}{l}\text { CV death, } \\
\text { nonfatal MI, or } \\
\text { nonfatal stroke }\end{array}$} & 37.4 vs. 43.9 & 26.9 vs. 31.5 & 22.6 vs. 24.2 \\
\hline & $(0.86[0.74-0.99])$ & $(0.86[0.75-0.97])$ & $(0.93[0.84-1.03])$ \\
\hline & $P<0.001$ for & $P<0.001$ for noninferiority & $P<0.001$ for noninferiority \\
\hline & noninferiority & $P=0.02$ for superiority & $P=0.17$ for superiority \\
\hline & $\begin{array}{c}P=0.04 \text { for } \\
\text { superiority }\end{array}$ & & \\
\hline \multirow{3}{*}{$\begin{array}{l}\text { CV death or } \\
\text { hospitalization } \\
\text { for } \mathrm{HF}\end{array}$} & 19.7 vs. 30.1 & 16.3 vs. 20.8 & 12.2 vs. 14.7 \\
\hline & $(0.66[0.55-0.79])$ & $(0.78[0.67-0.91])$ & $(0.83[0.73-0.95])$ \\
\hline & $P<0.001$ & & $P=0.005$ \\
\hline \multirow{3}{*}{$\begin{array}{l}\text { Hospitalization } \\
\text { for HF }\end{array}$} & 9.4 vs. 14.5 & 5.5 vs. 8.7 & 6.2 vs. 8.5 \\
\hline & $(0.65[0.50-0.85])$ & $(0.67[0.52-0.87])$ & $(0.73[0.61-0.88])$ \\
\hline & $P=0.002$ & & \\
\hline \multirow[t]{3}{*}{ CV death } & 12.4 vs. 20.2 & 11.6 vs. 12.8 & 7.0 vs. 7.1 \\
\hline & $(0.62[0.49-0.77])$ & $(0.87[0.72-1.06])$ & $(0.98[0.82-1.17])$ \\
\hline & $P<0.001$ & & \\
\hline
\end{tabular}


Table 1 continued

EMPA-REG

CANVAS [17, 59]

DECLARE-TIMI 58 [18, 60, 61]

OUTCOME

$[15,16]$

Renal outcomes, SGLT-2i vs. PBO, rate per 1000 PY (HR [95\% CI])

\begin{tabular}{|c|c|c|c|}
\hline \multirow[t]{9}{*}{$\begin{array}{l}\text { Composite } \\
\text { renal outcomes }\end{array}$} & $\begin{array}{l}\text { Incident or } \\
\text { worsening } \\
\text { nephropathy }{ }^{a} \text { or }\end{array}$ & $\begin{array}{l}40 \% \text { eGFR reduction, ESRD, or } \\
\text { death from renal or CV causes } \\
16.9 \text { vs. } 21.6\end{array}$ & $\begin{array}{l}\geq 40 \% \text { decrease in eGFR to }<60 \mathrm{ml} / \\
\min / 1.73 \mathrm{~m}^{2}, \text { new } \mathrm{ESRD} \text {, or death } \\
\text { from renal or CV causes }\end{array}$ \\
\hline & CV death & $(0.77[0.66-0.89])$ & 10.8 vs. 14.1 \\
\hline & 60.7 vs. 95.9 & & $(0.76[0.67-0.87])$ \\
\hline & $(0.61[0.55-0.69])$ & & \\
\hline & $P<0.001$ & & \\
\hline & $\begin{array}{l}\text { Incident or } \\
\text { worsening } \\
\text { nephropathy }^{\mathrm{a}}\end{array}$ & $\begin{array}{l}40 \% \text { eGFR reduction, ESRD, or } \\
\text { death from renal causes } \\
5.5 \text { vs. } 9.0\end{array}$ & $\begin{array}{l}\geq 40 \% \text { decrease in eGFR to }<60 \mathrm{ml} / \\
\min / 1.73 \mathrm{~m}^{2}, \text { new } \mathrm{ESRD} \text {, or death } \\
\text { from renal causes }\end{array}$ \\
\hline & 47.8 vs. 76.0 & $(0.60[0.47-0.77])$ & 3.7 vs. 7.0 \\
\hline & $(0.61[0.53-0.70])$ & & $(0.53[0.43-0.66])$ \\
\hline & $P<0.001$ & & \\
\hline \multirow{11}{*}{$\begin{array}{l}\text { Select additional } \\
\text { renal outcomes }\end{array}$} & Progression to & Progression of albuminuria ${ }^{c}$ & Progression of albuminuria ${ }^{\mathrm{d}}$ \\
\hline & macroalbuminuria $^{\mathrm{b}}$ & 89.4 vs. 128.7 & $(0.84[0.79-0.89])^{\mathrm{e}} P<0.0001$ \\
\hline & 41.8 vs. 64.9 & $(0.73[0.67-0.79])$ & \\
\hline & $(0.62[0.54-0.72])$ & & \\
\hline & $P<0.001$ & & \\
\hline & Doubling of sCr plus & $40 \%$ eGFR reduction & $\geq 40 \%$ decrease in eGFR to $<60 \mathrm{ml} /$ \\
\hline & $\mathrm{eGFR} \leq 45 \mathrm{ml} /$ & 5.3 vs. 8.7 & $\min / 1.73 \mathrm{~m}^{2}$ \\
\hline & $\min / 1.73 \mathrm{~m}^{2}$ & $(0.60[0.47-0.78])$ & $(0.54[0.43-0.67])^{\mathrm{e}}$ \\
\hline & 5.5 vs. 9.7 & & $P<0.0001$ \\
\hline & $(0.56[0.39-0.79])$ & & \\
\hline & $P<0.001$ & & \\
\hline
\end{tabular}

Other outcomes, SGLT-2i vs. PBO, mean difference (95\% CI)

\begin{tabular}{|c|c|c|c|}
\hline Body weight, kg & Values NR & $-1.6(-1.7$ to -1.5$) P<0.001$ & $-1.8(-2.0 \text { to }-1.7)^{\mathrm{f}}$ \\
\hline $\begin{array}{l}\text { Systolic BP, } \\
\mathrm{mmHg}\end{array}$ & Values NR & $-3.9(-4.3$ to -3.6$) P<0.001$ & $-2.7(-3.0 \text { to }-2.4)^{f}$ \\
\hline $\begin{array}{l}\text { Diastolic BP, } \\
\mathrm{mmHg}\end{array}$ & Values NR & $-1.4(-1.6$ to -1.2$) P<0.001$ & $-0.7(-0.9 \text { to }-0.6)^{\mathrm{f}}$ \\
\hline $\begin{array}{l}\text { HDL } \\
\text { cholesterol, } \\
\mathrm{mmol} / \mathrm{l}\end{array}$ & Values NR & $+0.05(+0.05$ to +0.06$)$ & NR \\
\hline
\end{tabular}


Table 1 continued

\begin{tabular}{llll}
\hline & $\begin{array}{l}\text { EMPA-REG } \\
\text { OUTCOME } \\
{[15,16]}\end{array}$ & CANVAS [17, 59] & DECLARE-TIMI 58 [18, 60, 61] \\
\hline $\begin{array}{l}\text { LDL } \\
\text { cholesterol, } \\
\mathrm{mmol} / \mathrm{l}\end{array}$ & Values NR & $+0.12(+0.09$ to +0.15$)$ & $\mathrm{NR}$ \\
\hline
\end{tabular}

${ }^{a}$ Defined as progression to macroalbuminuria (urine albumin-to-creatinine ratio $>300 \mathrm{mg} / \mathrm{g}$ ), doubling of serum creatinine in addition to eGFR $\leq 45 \mathrm{ml} / \mathrm{min} / 1.73 \mathrm{~m}^{2}$, initiation of renal replacement therapy, or death from renal causes

b Defined as urine albumin-to-creatinine ratio $>300 \mathrm{mg} / \mathrm{g}$

${ }^{c}$ Defined as $>30 \%$ increase in albuminuria plus a change from either normoalbuminuria to microalbuminuria or macroalbuminuria or from microalbuminuria to macroalbuminuria

$\mathrm{d}$ Progression from normoalbuminuria to microalbuminuria or macroalbuminuria

e Rate per 1000 PY not reported

${ }^{f}$ Least-squares mean difference

$B P$ blood pressure, $C I$ confidence interval, $C V$ cardiovascular, $C V D$ cardiovascular disease, $e G F R$ estimated glomerular filtration rate, $E S R D$ end-stage renal disease, $H D L$ high-density lipoprotein, $H F$ heart failure, $H R$ hazard ratio, $L D L$ lowdensity lipoprotein, $M I$ myocardial infarction, $N R$ not reported, $P B O$ placebo, $P Y$ patient-years, $S G L T-2 i$ sodium-glucose cotransporter- 2 inhibitor, $T 2 D$ type 2 diabetes

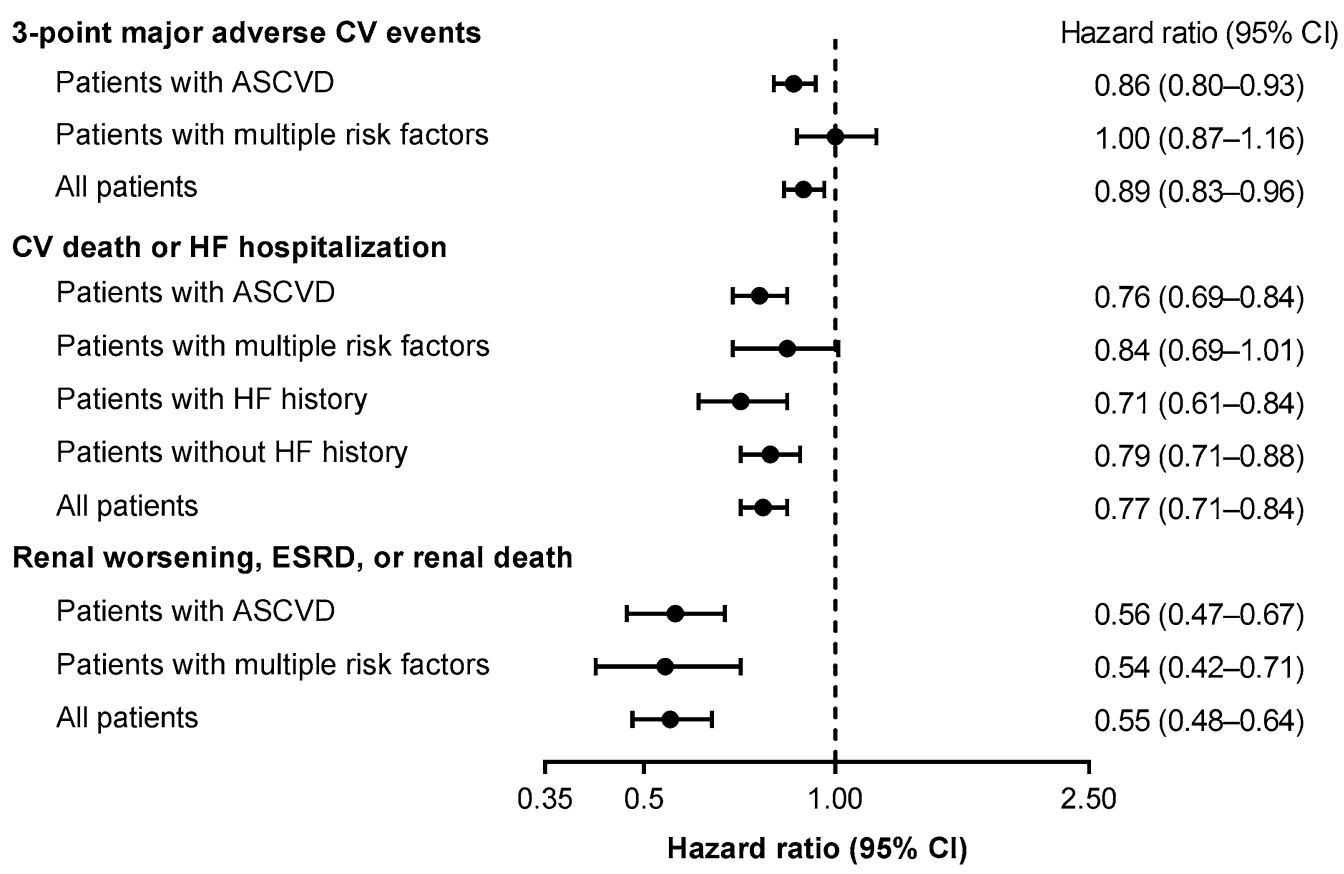

Fig. 3 Summary of cardiovascular and renal outcomes with SGLT-2is as determined by a meta-analysis of the EMPAREG OUTCOME, CANVAS, and DECLARE-TIMI 58

$C I$ confidence interval, $C V$ cardiovascular, ESRD end-stage renal disease, $H F$ heart failure, $S G L T-2 i$ sodium-glucose studies [30]. ASCVD atherosclerotic cardiovascular disease, cotransporter-2 inhibitor 
Table 2 Summary of the pleiotropic effects of SGLT-2is in real-world studies of patients with T2D

\begin{tabular}{|c|c|c|c|c|}
\hline Study & No. of patients & Outcomes & HR (95\% CI) & $P$ value \\
\hline \multirow[t]{4}{*}{ CVD-REAL [32] } & 309,056 & SGLT-2is vs. oGLT ${ }^{a}$ & & \\
\hline & & Hospitalization for HF & $0.61(0.51-0.73)$ & $<0.001$ \\
\hline & & All-cause mortality & $0.49(0.41-0.57)$ & $<0.001$ \\
\hline & & Hospitalization for HF or death & $0.54(0.48-0.60)$ & $<0.001$ \\
\hline \multirow{14}{*}{$\begin{array}{l}\text { CVD-REAL (Nordic) } \\
\quad[33,34]\end{array}$} & 91,320 & SGLT-2is vs. oGLT ${ }^{\mathrm{a}}$ & & \\
\hline & & MACE & $0.78(0.69-0.87)$ & $<0.0001$ \\
\hline & & Nonfatal MI & $0.87(0.73-1.03)$ & 0.112 \\
\hline & & Nonfatal stroke & $0.86(0.72-1.04)$ & 0.965 \\
\hline & & CV mortality & $0.53(0.40-0.71)$ & $<0.0001$ \\
\hline & & Hospitalization for HF & $0.70(0.61-0.81)$ & $<0.0001$ \\
\hline & & All-cause mortality & $0.51(0.45-0.58)$ & $<0.0001$ \\
\hline & 40,908 & Dapagliflozin vs. DPP-4is & & \\
\hline & & MACE & $0.79(0.67-0.94)$ & 0.006 \\
\hline & & Nonfatal MI & $0.91(0.72-1.16)$ & 0.445 \\
\hline & & Nonfatal stroke & $0.79(0.61-1.03)$ & 0.086 \\
\hline & & CV mortality & $0.76(0.53-1.08)$ & 0.122 \\
\hline & & Hospitalization for $\mathrm{HF}$ & $0.62(0.50-0.77)$ & $<0.001$ \\
\hline & & All-cause mortality & $0.59(0.49-0.72)$ & $<0.001$ \\
\hline \multirow[t]{6}{*}{ CVD-REAL 2 [36] } & 470,128 & SGLT-2i vs. oGLT ${ }^{\mathrm{a}}$ & & \\
\hline & & MI & $0.81(0.74-0.88)$ & $<0.001$ \\
\hline & & Stroke & $0.68(0.55-0.84)$ & $<0.001$ \\
\hline & & Hospitalization for $\mathrm{HF}$ & $0.64(0.50-0.82)$ & 0.001 \\
\hline & & All-cause mortality & $0.51(0.37-0.70)$ & $<0.001$ \\
\hline & & Hospitalization for HF or death & $0.60(0.47-0.76)$ & $<0.001$ \\
\hline \multirow[t]{9}{*}{ EMPRISE [41] } & 32,886 & Empagliflozin vs. sitagliptin & & \\
\hline & & Hospitalization for HF (specific) ${ }^{b}$ & $0.50(0.28-0.91)$ & $<0.001$ \\
\hline & & Hospitalization for HF (broad) ${ }^{c}$ & $0.51(0.39-0.68)$ & $<0.001$ \\
\hline & 35,102 & Empagliflozin vs. DPP-4is & & \\
\hline & & Hospitalization for HF (specific) ${ }^{b}$ & $0.49(0.27-0.89)$ & 0.002 \\
\hline & & Hospitalization for HF (broad) ${ }^{c}$ & $0.56(0.43-0.73)$ & $<0.001$ \\
\hline & 224,528 & SGLT-2is vs. DPP-4is & & \\
\hline & & Hospitalization for HF (specific) ${ }^{b}$ & $0.42(0.35-0.50)$ & $<0.001$ \\
\hline & & Hospitalization for HF (broad) ${ }^{\mathrm{c}}$ & $0.70(0.65-0.75)$ & $<0.001$ \\
\hline
\end{tabular}


Table 2 continued

\begin{tabular}{|c|c|c|c|c|}
\hline Study & No. of patients & Outcomes & HR (95\% CI) & $P$ value \\
\hline \multirow[t]{2}{*}{ Gautam et al. [37] } & 14,697 & SGLT-2is vs. DPP-4is & & \\
\hline & & Hospitalization for $\mathrm{HF}$ & $0.68(0.54-0.86)$ & 0.001 \\
\hline \multirow[t]{8}{*}{ Norhammar et al. [39] } & 28,408 & Dapagliflozin vs. oGLT ${ }^{\mathrm{a}}$ & & \\
\hline & & MACE & $0.90(0.79-1.03)$ & 0.129 \\
\hline & & MI & $0.91(0.74-1.11)$ & 0.347 \\
\hline & & Stroke & $1.06(0.87-1.30)$ & 0.531 \\
\hline & & CV mortality & $0.75(0.57-0.97)$ & 0.003 \\
\hline & & Hospitalization for HF & $0.79(0.67-0.93)$ & 0.005 \\
\hline & & Hospitalization for HF or CV mortality & $0.79(0.69-0.92)$ & 0.002 \\
\hline & & All-cause mortality & $0.63(0.54-0.74)$ & $<0.001$ \\
\hline \multirow[t]{9}{*}{ Patorno et al. [40] } & 77,956 & Canagliflozin vs. DPP-4is & & \\
\hline & & Hospitalization for $\mathrm{HF}$ & $0.70(0.54-0.92)$ & NR \\
\hline & & Composite CV end point ${ }^{\mathrm{d}}$ & $0.89(0.68-1.17)$ & NR \\
\hline & & Canagliflozin vs. GLP-1RAs & & \\
\hline & & Hospitalization for $\mathrm{HF}$ & $0.61(0.47-0.78)$ & NR \\
\hline & & Composite CV end point ${ }^{\mathrm{d}}$ & $1.03(0.79-1.35)$ & NR \\
\hline & & Canagliflozin vs. SUs & & \\
\hline & & Hospitalization for $\mathrm{HF}$ & $0.51(0.38-0.67)$ & NR \\
\hline & & Composite CV end point ${ }^{\mathrm{d}}$ & $0.86(0.65-1.13)$ & NR \\
\hline \multirow[t]{2}{*}{ Kim et al. [38] } & 118,958 & SGLT-2is vs. DPP-4is & & \\
\hline & & Hospitalization for $\mathrm{HF}$ & $0.66(0.58-0.75)$ & $<0.001$ \\
\hline
\end{tabular}

a Any oral or injectable glucose-lowering medication, including fixed-dose combinations, other than SGLT-2is

b Defined as an HF discharge diagnosis in the primary position

c Defined as an HF discharge diagnosis in any position

d Defined as hospitalization for acute MI, ischemic stroke, or hemorrhagic stroke

$C I$ confidence interval, $C V$ cardiovascular, $D P P-4 i$ dipeptidyl peptidase-4 inhibitor, GLP-1RA glucagon-like peptide-1 receptor agonist, $H F$ heart failure, $H R$ hazard ratio, $M A C E$ major adverse cardiovascular events, $M I$ myocardial infarction, $N R$ not reported, $o G L T$ other glucose-lowering therapy, $S G L T-2 i$ sodium-glucose cotransporter-2 inhibitor, $S U$ sulfonylurea, $T 2 D$ type 2 diabetes

or death was observed in patients regardless of CVD status at baseline [35]. A subanalysis (CVDREAL Nordic) showed significant reductions in the risk of MACE (by 22\%) and CV mortality (by $47 \%$ ) with SGLT-2is versus other glucose-lowering therapy [33] and in the risk of MACE (by
21\%) and hospitalization for HF (by 38\%) with SGLT-2is versus dipeptidyl peptidase-4 inhibitors (DPP-4is) [34].

In the multinational CVD-REAL 2 study, the risk of hospitalization for $\mathrm{HF}$, the composite outcome of hospitalization for HF or death, and 


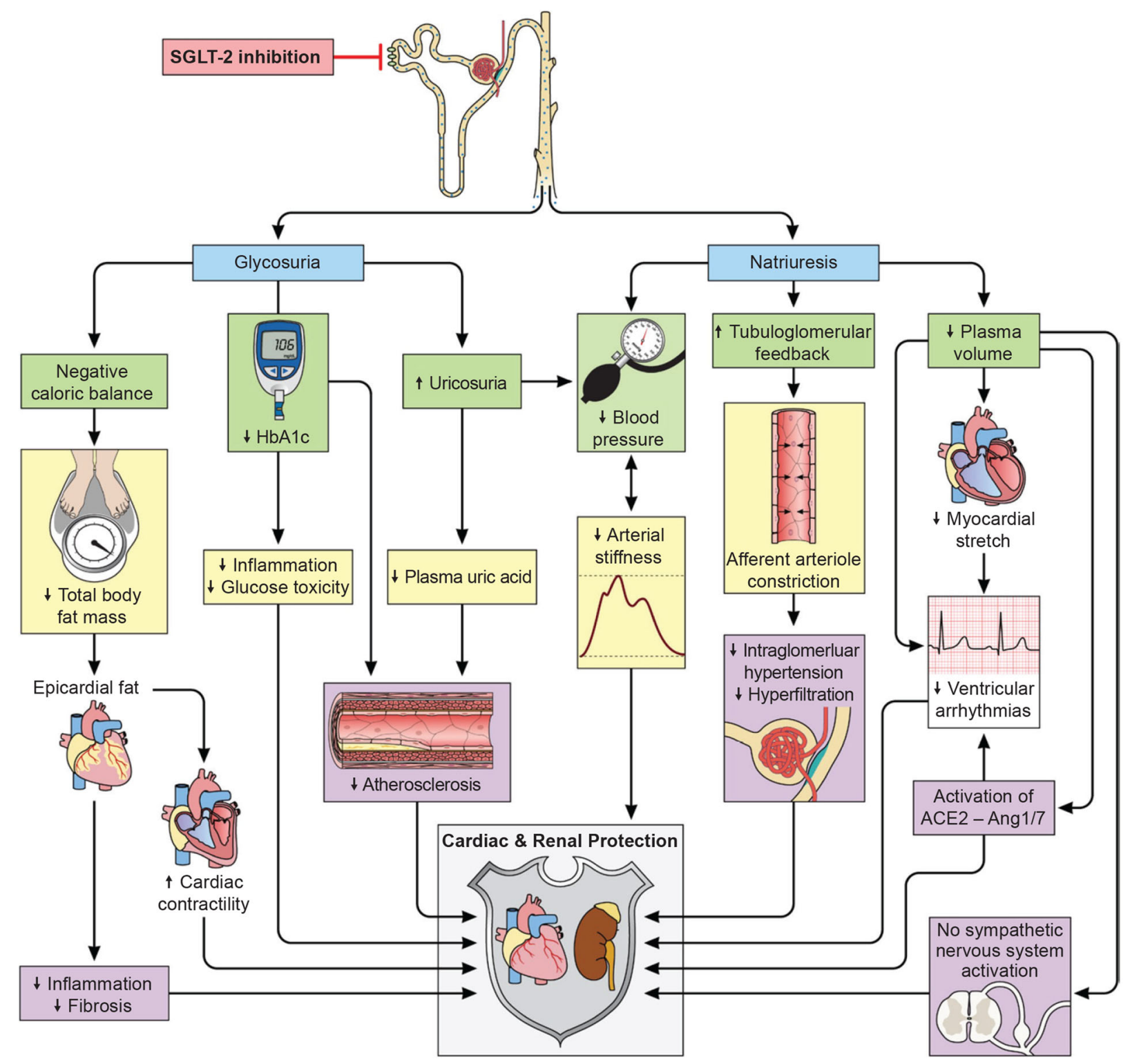

Fig. 4 Potential mechanisms for pleiotropic effects of sodium-glucose cotransporter-2 inhibitors in patients with type 2 diabetes. Reproduced with permission from

MI was reduced with SGLT-2is to a similar extent to that seen in the CVD-REAL study compared with other glucose-lowering therapy (Table 2) [36]. In addition, the risk of stroke was reduced by $32 \%$. Several retrospective studies have also demonstrated similar improvements in $\mathrm{CV}$ mortality and hospitalization for $\mathrm{HF}$ outcomes with SGLT-2i therapy (Table 2) [37-41].
Heerspink et al. 2016 [42]. ACE2 angiotensin-converting enzyme 2, Angl/7 angiotensin 1/7, HbAlc glycated hemoglobin, $S G L T-2$ sodium-glucose cotransporter-2

\section{Potential Mechanisms of Cardiovascular Effects}

The mechanisms underlying the beneficial CV effects of SGLT-2is in patients with T2D are not fully understood, but likely involve multiple contributing factors, including favorable effects on $\mathrm{CV}$ risk factors such as body weight, BP, and lipids (Fig. 4) [42]. One of the key mechanisms 
Table 3 Summary of ongoing outcomes trials of sodium-glucose cotransporter-2 inhibitors

\begin{tabular}{|c|c|c|}
\hline $\begin{array}{l}\text { Study name } \\
\text { (Clinical Trials.gov } \\
\text { identifier) }\end{array}$ & Drug & $\begin{array}{l}\text { Patient } \\
\text { population }\end{array}$ \\
\hline $\begin{array}{l}\text { DAPA-CKD } \\
\quad(\text { NCT03036150) }\end{array}$ & Dapagliflozin & CKD \\
\hline $\begin{array}{l}\text { DAPA-HF } \\
\quad(\text { NCT03036124) }\end{array}$ & Dapagliflozin & HFrEF \\
\hline $\begin{array}{l}\text { DELIVER } \\
\text { (NCT03619213) }\end{array}$ & Dapagliflozin & HFpEF \\
\hline $\begin{array}{l}\text { DETERMINE- } \\
\text { reduced } \\
\text { (NCT03877237) }\end{array}$ & Dapagliflozin & HFrEF \\
\hline $\begin{array}{l}\text { DETERMINE- } \\
\text { preserved } \\
\text { (NCT03877224) }\end{array}$ & Dapagliflozin & HFpEF \\
\hline $\begin{array}{l}\text { EMPA-KIDNEY } \\
\qquad(\text { NCT03594110) }\end{array}$ & Empagliflozin & CKD \\
\hline $\begin{array}{l}\text { EMPEROR- } \\
\text { Preserved } \\
\text { (NCT03057951) }\end{array}$ & Empagliflozin & HFpEF \\
\hline $\begin{array}{l}\text { EMPEROR- } \\
\text { Reduced } \\
\text { (NCT03057977) }\end{array}$ & Empagliflozin & HFrEF \\
\hline $\begin{array}{l}\text { SCORED } \\
\qquad(\text { NCT03315143) }\end{array}$ & Sotagliflozin & $\begin{array}{l}\text { T2D, moderate } \\
\text { renal } \\
\text { impairment, } \mathrm{CV} \\
\text { risk }\end{array}$ \\
\hline $\begin{array}{l}\text { SOLOIST-WHF } \\
\text { (NCT03521934) }\end{array}$ & Sotagliflozin & $\begin{array}{l}\text { T2D after } \\
\text { worsening HF }\end{array}$ \\
\hline $\begin{array}{l}\text { VERTIS-CV } \\
\qquad \text { (NCT01986881) }\end{array}$ & Ertugliflozin & $\begin{array}{l}\text { T2D and } \\
\text { established } \\
\text { ASCVD }\end{array}$ \\
\hline
\end{tabular}

$A S C V D$ atherosclerotic cardiovascular disease, $C K D$ chronic kidney disease, $C V$ cardiovascular, $H F$ heart failure, $H F p E F$ HF with preserved ejection fraction, $H F r E F$ $\mathrm{HF}$ with reduced ejection fraction, T2D type 2 diabetes

for the observed CV benefits with SGLT-2is is believed to be improvement in ventricular loading through decreases in cardiac load [43].
Increased natriuresis and glucosuria, caused by inhibition of glucose and sodium renal reabsorption in the proximal tubule by SGLT-2is, lead to increased osmotic diuresis and reductions in preload, while reductions in BP (described later) and changes in vascular function are believed to decrease afterloading [43].

SGLT-2i therapy may increase cardiac efficiency through decreased cardiac load and increased oxygen delivery by hemoconcentration $[44,45]$. SGLT-2is have been shown to reduce $\mathrm{BP}$ and improve markers of arterial stiffness, vascular resistance, and cardiac workload in patients with T2D [46-51]. Reductions in BP with SGLT-2is may play a role in their cardioprotective effects, although improvements in CV outcomes with empagliflozin versus placebo in EMPA-REG OUTCOME were observed earlier than is usually seen in studies of BP-lowering therapy [52].

SGLT-2i therapy may also improve cardiac efficiency by causing a systemic shift in fuel metabolism from glucose to fatty acid oxidation $[43,53,54]$, while mild, persistent increases in blood ketone levels (which occur with SGLT-2i use) are believed to promote cardiac uptake and oxidization of ketone bodies, such as $\beta$-hydroxybutyrate, as an alternative fuel to fatty acids $[44,45]$.

Increased urinary glucose excretion with SGLT-2is potentially reduces cardiac glucotoxicity, consequently decreasing the risk of HF in patients with T2D and high CVD risk [55]. In addition, studies of animal models have suggested that SGLT-2is may act directly on cardiac tissues to reduce oxidative stress and inflammation $[56,57]$.

\section{Ongoing Studies of Cardiovascular Effects}

Several randomized, placebo-controlled clinical studies are currently investigating CV outcomes with SGLT-2is (Table 3). CV and HF outcomes with empagliflozin and dapagliflozin are being assessed in patients with HF with preserved ejection fraction (HFpEF) and in those with HFrEF. Several studies are investigating longterm CV and renal outcomes with ertugliflozin or sotagliflozin (an SGLT-1 and SGLT-2 
inhibitor) in patients with T2D and established CVD, CV risk, or HF [58].

Data from these studies may provide additional evidence of the beneficial $\mathrm{CV}$ effects of SGLT-2is in patients with CVD or HF (with or without T2D) and potentially address gaps in knowledge from the CVOTs of SGLT-2is.

\section{RENAL EFFECTS OF SGLT-2 INHIBITORS}

\section{Randomized Clinical Trials}

In CVOTs, SGLT-2is were associated with a significant reduction in the risk of kidney disease progression compared with placebo in patients with T2D and established CVD or varying levels of CV risk (Table 1) [16-18]. Empagliflozin reduced the risk of a composite renal outcome comprising macroalbuminuria, doubling of serum creatinine plus eGFR reduction, initiation of renal replacement therapy, or death from renal causes [16]. Canagliflozin and dapagliflozin each reduced the risk of composite renal outcomes comprising estimated glomerular filtration rate (eGFR) reduction, end-stage renal disease (ESRD), or death from renal causes [17, 18, 59]. EMPA-REG OUTCOME, CANVAS, and DECLARE-TIMI 58 also reported additional renal outcomes, including reductions in the risks of individual components of the composite outcomes, and analyses across prespecified patient subgroups [16, 17, 59-61].

In a meta-analysis of data from these three CVOTs, the overall risk of worsening of renal function, ESRD, or death from renal causes was reduced by $45 \%$ with SGLT-2is versus placebo (Fig. 3) [30, 31]. In this meta-analysis, similar renoprotective effects were found among patients with atherosclerotic CVD and those with multiple CVD risk factors [30]. In a metaanalysis of 25 randomized controlled trials of patients with T2D (with or without CKD), SGLT-2i therapy was associated with reduced risk of albuminuria progression (by 29\%) and increased likelihood of regression of albuminuria (by 71\%) compared with placebo [62]. This analysis also showed reductions in risk of the composite outcome of a sustained $40 \%$ reduction in eGFR, the need for renal replacement therapy, or death from renal causes (by 43\%) and all-cause mortality (by 16\%). The risk reductions for these outcomes were consistently observed regardless of baseline renal function, with no significant differences between different eGFR subgroups [62].

The CREDENCE trial investigated the effects of canagliflozin on renal failure and $\mathrm{CV}$ events in patients with T2D and established CKD (eGFR 30 to $<90 \mathrm{ml} / \mathrm{min} / 1.73 \mathrm{~m}^{2}$ and macroalbuminuria) and was stopped early after achievement of the primary end point, which consisted of a composite renal outcome, with renal events adjudicated. Canagliflozin was associated with a $30 \%$ reduction in the risk of the composite outcome of new ESRD, doubling of serum creatinine, or death from renal or CV causes compared with placebo [63].

In addition, the randomized, placebo-controlled DELIGHT trial assessed the effects of dapagliflozin or dapagliflozin + saxagliptin on albuminuria over 24 weeks in patients with T2D and moderate-to-severe CKD (urine albumin-tocreatinine ratio [UACR] of $30-3500 \mathrm{mg} / \mathrm{g}$ and eGFR of $25-75 \mathrm{ml} / \mathrm{min} / 1.73 \mathrm{~m}^{2}$ ) [64]. Both treatments reduced the UACR, with differences from placebo for the mean percentage change from baseline of $-21.0 \%(P=0.011)$ in the dapagliflozin group and $-38.0 \%(P<0.0001)$ in the dapagliflozin + saxagliptin group.

\section{Potential Mechanisms of Renal Effects}

The mechanisms underlying improved renal outcomes with SGLT-2is are likely multifactorial and potentially associated with their direct hemodynamic and renovascular effects (Fig. 4) $[2,42]$. Increased natriuresis leads to increased sodium levels at the macula densa, which results in activation of tubuloglomerular feedback and reductions in renal blood flow and glomerular hyperfiltration [2, 65]. Combined use of SGLT-2is with angiotensin-converting enzyme inhibitors or angiotensin receptor blockers may further reduce intraglomerular pressure [43]. Additive renal improvements with SGLT-2is and renin-aldosterone-angiotensin system inhibitors may result from 
simultaneous blockade of sodium-hydrogen exchangers (NHE1 and NHE3) in the kidney [66]. Hyperglycemia, hyperinsulinemia, and adipokines stimulate NHE activity, which may contribute to glomerular hyperfiltration and other features of diabetic nephropathy. Furthermore, the NHE1 isoform is also expressed in the heart and vasculature and contributes to the pathophysiology of HF.

SGLT-2i-associated changes in renal hemodynamics lead to acute reductions in eGFR (that stabilize with long-term treatment) and albuminuria (that are sustained with longer treatment) and are not observed with other classes of glucose-lowering therapy [67]. SGLT-2is may also increase glucagon secretion, which may contribute to vasodilation, fasting-state natriuresis, protein-induced hyperfiltration, and nitrogen end-product excretion [2,68].

\section{Ongoing Studies of Renal Effects}

Two multicenter, randomized, double-blind, placebo-controlled outcomes trials are currently investigating the effects of dapagliflozin and empagliflozin on renal outcomes and CV mortality in patients with CKD (with or without T2D; Table 3). Two studies are investigating CV and renal outcomes with sotagliflozin in patients with T2D and worsening HF and in patients with T2D, moderate renal impairment, and $\mathrm{CV}$ risk. The results of these studies may help to establish SGLT-2is as effective therapy in patients with CKD (with or without T2D).

\section{BODY WEIGHT EFFECTS OF SGLT-2 INHIBITORS}

In CVOTs of SGLT-2is, empagliflozin, canagliflozin, and dapagliflozin were associated with small reductions in body weight from baseline compared with placebo (Table 1) $[15,17,18]$. A meta-analysis of 43 randomized clinical trials with durations of 4-208 weeks also indicated that SGLT-2i therapy was associated with reductions in body weight, with a weighted mean $(95 \% \mathrm{CI})$ difference of $-1.88(-2.11$ to - 1.66) $\mathrm{kg}$ versus comparators across studies [22]. Given the favorable effects of SGLT-2is on body weight, they may be particularly beneficial in patients with T2D who are overweight or obese, especially when used in combination with other medications that increase satiety [69].

The reductions in body weight with SGLT-2is are believed to result from an increase in urinary glucose excretion [12]. SGLT-2is are associated with daily glucose losses of $\sim 60-80 \mathrm{~g}$ or 240-320 calories [12], yet body weight reductions observed after 12-24 weeks of SGLT-2i therapy are typically in the $2-$ to $3-\mathrm{kg}$ range [70-72]. Discrepancies between expected and observed weight loss may be accounted for by an increase in energy intake or compensatory mechanisms [73]. Although fluid loss may initially play a role in weight loss, overall reductions in body weight are believed to be mainly the result of fat loss [74-76].

\section{BLOOD PRESSURE EFFECTS OF SGLT-2 INHIBITORS}

In CVOTs, SGLT-2is were associated with reductions in systolic and diastolic BP compared with placebo (Table 1$)[15,17,18]$. In a metaanalysis of 43 randomized clinical trials (4208 weeks in duration), SGLT-2is were associated with reductions in systolic BP of -2.46 $\mathrm{mmHg}(95 \% \mathrm{CI},-2.86$ to $-2.06 \mathrm{mmHg})$ and diastolic BP of $-1.46 \mathrm{mmHg}(95 \% \mathrm{CI},-1.82$ to - $1.09 \mathrm{mmHg}$ ) versus comparators across studies [22].

Reductions in systolic BP and cardiac load may be caused by the diuretic effects of SGLT2 is through increased urinary excretion of glucose and sodium [55]. Increased natriuresis with SGLT-2is also leads to sustained reductions in intravascular volume, which likely contribute to the antihypertensive effects of SGLT-2is [77]. 
OTHER EFFECTS OF SGLT-2 INHIBITORS, INCLUDING INSULIN SENSITIVITY, HDL CHOLESTEROL, HEPATIC FAT, HYPERURICEMIA, AND CARDIAC REMODELING

Reductions in glucotoxicity with SGLT-2is have been shown to result in improved insulin sensitivity and enhanced beta-cell function $[54,78,79]$. In patients with T2D, induction of glucosuria with dapagliflozin for 2 weeks significantly increased insulin-mediated glucose storage in skeletal muscle $[78,79]$ and significantly improved beta-cell function compared with placebo [78]. Similarly, empagliflozin was associated with improvements in insulin sensitivity and beta-cell function after a single dose, despite a decrease in insulin secretion and tissue glucose disposal, and an increase in endogenous glucose production [54].

SGLT-2is have been associated with improvements in HDL cholesterol in randomized trials $[15,17,22,80]$. In CANVAS, canagliflozin was associated with higher levels of HDL cholesterol compared with placebo, and although LDL cholesterol also increased, the LDL-to-HDL cholesterol ratio remained unchanged (Table 1) [17]. Similarly, in EMPAREG OUTCOME, empagliflozin was associated with small increases in both HDL cholesterol and LDL cholesterol compared with placebo [15]. In a 12-week randomized study of Japanese patients with T2D, there was a significant reduction in small, dense LDL cholesterol from baseline $(-19.9 \% ; P=0.005)$ and a significant increase in HDL cholesterol (+ 10.5\%; $P<0.001)$ with dapagliflozin [80]. A metaanalysis of randomized trials (4-208 weeks in duration) indicated that HDL cholesterol was increased by $0.10 \mathrm{mmol} / \mathrm{l} \quad(95 \%$ CI, $0.08-$ $0.12 \mathrm{mmol} / \mathrm{l}) \quad(3.89 \mathrm{mg} / \mathrm{dl} \quad[95 \% \quad \mathrm{CI}$ $3.23-4.56 \mathrm{mg} / \mathrm{dl}]$ ) with SGLT-2is versus comparators across studies [22].

SGLT-2is also have the potential to specifically reduce the accumulation of hepatic fat, particularly in patients with T2D and nonalcoholic fatty liver disease [81, 82]. Significantly greater reductions in hepatic fat were observed with empagliflozin plus standard glucose- lowering therapy than with standard therapy alone after 20 weeks (mean difference, $-4.0 \%$; $P<0.0001$ ) in patients with T2D and nonalcoholic fatty liver disease [81], and dapagliflozin resulted in a significant, placebo-corrected reduction in hepatic fat after 8 weeks $(-3.7 \%$; $P<0.01)$ in obese patients with T2D [82].

Given that hyperuricemia is a contributing factor in the development of hypertension, $\mathrm{CVD}$, and $\mathrm{CKD}$, reduction in uric acid is another potential mechanism of $\mathrm{CV}$ and renal benefits with SGLT-2is [83]. Small reductions in uric acid were observed with empagliflozin in EMPA-REG OUTCOME [15]. A meta-analysis of 12 randomized clinical trials of 4-78 weeks' duration also indicated that empagliflozin significantly reduced serum uric acid levels, with differences from placebo of $-36.6 \mu \mathrm{mol} / 1$ with empagliflozin $10 \mathrm{mg}$ and $-43.6 \mu \mathrm{mol} / \mathrm{l}$ with empagliflozin $25 \mathrm{mg}$ (both $P<0.001$ ) [83]. Reductions in serum uric acid have also been observed with dapagliflozin and canagliflozin [84-86].

Because SGLT-2i use is associated with improvements in glycemic control, insulin resistance, body weight, and BP, it is believed that these agents may also promote regression of left ventricular hypertrophy [87-89] and cardiac and arterial remodeling $[48,90]$. Animal studies have indicated that SGLT-2is mitigate cardiac fibrosis and coronary artery remodeling $[57,91]$ and preserve cardiac function [92]. Furthermore, post hoc analyses of randomized clinical trials have shown favorable effects of empagliflozin on arterial stiffness, vascular resistance, and markers of cardiac load [46, 47]. In a preliminary analysis of data from the EMPA-HEART Cardiolink 6 trial, empagliflozin was associated with significantly greater reductions in left ventricular mass compared with placebo among patients with T2D and coronary artery disease [93].

\section{SAFETY CONSIDERATIONS FOR SGLT-2 INHIBITORS}

SGLT-2is are generally well tolerated and have demonstrated a low risk of hypoglycemia in CVOTs $[15,17,18]$. An increased risk of some adverse events (AEs), such as genitourinary 
infections, has been reported with SGLT-2is versus other glucose-lowering treatments or placebo $[62,94]$. However, conflicting findings have been reported for urinary tract infections, with similar risks found among patients initiating SGLT-2is compared with those initiating DPP-4is or glucagon-like peptide- 1 receptor agonists in a large cohort of patients seen in routine clinical practice [95]. In rare cases, some serious AEs, including diabetic ketoacidosis (DKA), acute kidney injury (AKI), lower extremity amputations, fractures, bladder cancer, and Fournier gangrene, have also been reported.

Cases of euglycemic DKA have been reported with SGLT-2i use, and awareness that DKA can occur in the absence of significant hyperglycemia is critical for recognition of this potentially serious AE [96]. All three CVOTs reported a low incidence of DKA $[15,17,18]$. However, a meta-analysis of the CVOTs found an increased risk of DKA with SGLT-2is versus placebo (hazard ratio [HR], 2.20 [95\% CI, 1.25-3.87]; $P=0.0060$ ), although the rate of DKA events in each CVOT was low $(<1$ event per 1000 patient-years) [30]. Clinicians and patients should be aware that DKA is a possible complication of SGLT-2i therapy and should be able to recognize the symptoms of DKA, including nausea, vomiting, dyspnea, or malaise [96].

While postmarketing reports of AKI with SGLT-2is prompted the inclusion of a warning for AKI in the USA prescribing information for each drug [97-100], CVOTs of empagliflozin, canagliflozin, and dapagliflozin demonstrated no increase in the incidence of AKI versus placebo $[15,17,18,59]$. In addition, a real-world study of patients with T2D showed SGLT-2is were associated with lower rates of hospitalization with AKI compared with DPP-4is [101]. Clinicians should consider factors that may predispose patients to AKI, including chronic renal insufficiency, hypovolemia, congestive HF, or concomitant medications (e.g., diuretics, angiotensin-converting enzyme inhibitors, angiotensin II receptor blockers, and nonsteroidal anti-inflammatory drugs) and discontinue SGLT-2i treatment in patients who develop AKI [97-100].
The risk of lower extremity amputation may differ among the SGLT- 2 class. An increased risk of lower extremity amputation was observed with canagliflozin versus placebo (6.3 vs. 3.4 events per 1000 patient-years; HR, 1.97 [95\% CI, 1.41-2.75]) in CANVAS [17]. However, in the CREDENCE trial, the risk of amputation with canagliflozin versus placebo was not significantly higher (12.3 vs. 11.2 events per 1000 patient-years; HR, 1.11 [95\% CI, 0.79-1.56]) [63]. Furthermore, a real-world meta-analysis of four observational databases (OBSERVE-4D) found no increased risk of below-knee lower extremity amputation with canagliflozin versus non-SGLT-2i glucose-lowering medications (HR, 1.01 [95\% CI, 0.93-1.10]) [102]. In contrast to CANVAS, empagliflozin and dapagliflozin showed no increase in the incidence of amputations in EMPA-REG OUTCOME or DECLARE-TIMI 58, respectively $[18,103]$. A metaanalysis of the three CVOTs reported significant heterogeneity $\left(I^{2}=79.1 \%\right)$ for amputations; only CANVAS showed an increased risk for amputation with canagliflozin [30]. Across seven ertugliflozin phase 3 clinical trials, nontraumatic lower extremity amputations were observed among patients treated with ertugliflozin $5 \mathrm{mg}$ ( $n=3 ; 0.2 \%$ of patients), ertugliflozin $15 \mathrm{mg}$ ( $n=8 ; 0.5 \%$ of patients), and comparator ( $n=1 ; 0.1 \%$ of patients) [100].

The risk of fractures also appears to vary among the SGLT-2i class. Canagliflozin was associated with an increased risk of fractures compared with placebo in CANVAS (15.4 vs. 11.9 events per 1000 patient-years; HR, 1.26 [95\% CI, 1.04-1.52]) [17]. However, in the CREDENCE trial, no increased risk of fracture was observed with canagliflozin versus placebo (11.8 vs. 12.1 events per 1000 patient-years; HR, 0.98 [95\% CI, 0.70-1.37]) [63]. Empagliflozin and dapagliflozin showed no increase in the risk of fractures in EMPA-REG OUTCOME or DECLARE-TIMI 58, respectively [15, 18]. Furthermore, dapagliflozin demonstrated no increase in the risk of treatment-emergent fractures in a population-based cohort study [104]. In a meta-analysis of the three CVOTs, significant heterogeneity $\left(I^{2}=78.2 \%\right)$ was found for fractures, with an increased risk of fracture observed only in CANVAS [30]. 
Postmarketing reports of Fournier gangrene associated with SGLT-2i use led to the inclusion of a warning for Fournier gangrene in the US prescribing information for each SGLT-2i [105]. Although cases of Fournier gangrene are rare, an analysis of the US Food and Drug Administration Adverse Event Reporting System and published case studies reported 55 cases of Fournier gangrene among patients treated with SGLT-2is in the 6 years since their approval compared with 19 cases associated with other glucoselowering therapies over 35 years [106]. In DECLARE-TIMI 58, six cases of Fournier gangrene were reported, one with dapagliflozin treatment and five with placebo [18]. EMPAREG OUTCOME and CANVAS did not report any cases of Fournier gangrene $[15,17]$. Due to the substantial morbidity and mortality associated with Fournier gangrene, clinicians should be alert to recognizing the early signs and symptoms, including systemic symptoms (fatigue, fever, and malaise), local symptoms (tenderness, erythema, and swelling), and pain that seems disproportionate to findings on physical examination [106].

An imbalance in bladder cancers was observed in an analysis of the phase $2 b / 3$ dapagliflozin trials, with a higher incidence of bladder cancer reported in patients receiving dapagliflozin versus those treated with a comparator (9 of 5936 patients vs. 1 of 3403 patients; incidence rate ratio, 5.17 [95\% CI, 0.68-233.55]) [107]. Conversely, among $>17,000$ patients included in DECLARE-TIMI 58 over 4 years, a lower incidence of bladder cancer was observed with dapagliflozin versus placebo [18]. Likewise, no imbalance in bladder cancer rates was observed with empagliflozin or canagliflozin versus placebo in EMPA-REG OUTCOME or CANVAS, respectively $[17,108]$.

\section{CONCLUSIONS}

As demonstrated in large randomized clinical trials and real-world observational studies, SGLT-2is have multiple nonglycemic effects in patients with T2D, including improvements in $\mathrm{CV}$ and renal outcomes and reductions in BP and body weight. These pleiotropic effects are beneficial for the prevention or reduction of macro- and microvascular complications and may be of particular benefit in patients with or at risk for complications of diabetes, such as CVD, HF, or CKD. Ongoing outcomes trials in specific patient populations may help to confirm the benefits of SGLT-2is for the prevention of CVD, HF, and CKD in patients with or without T2D and provide further insights into the potential mechanisms for these pleiotropic effects.

\section{ACKNOWLEDGEMENTS}

Funding. The development of this manuscript and the Rapid Service Fees were supported by AstraZeneca.

Medical Writing Assistance. Sarah Greig, $\mathrm{PhD}$, of inScience Communications (Auckland, New Zealand) provided medical writing support, which was in accordance with Good Publication Practice (GPP3) guidelines and funded by AstraZeneca.

Authorship. All named authors meet the International Committee of Medical Journal Editors (ICMJE) criteria for authorship for this article, take responsibility for the integrity of the work as a whole, and have given their approval for this version to be published. All authors had full access to the articles reviewed in this manuscript and take complete responsibility for the integrity and accuracy of this manuscript.

Disclosures. Dhiren Patel has served on speaker's bureaus for AstraZeneca, Boehringer Ingelheim, Merck, Novo Nordisk, and Valeritas and as a consultant on medical advisory boards for AstraZeneca, Becton Dickinson, Eli Lilly, Merck, Novo Nordisk, and Sanofi. Jodi Strong has served on speaker's bureaus for Abbott, American Diabetes Association, AstraZeneca, BILilly, Janssen, Merck, Novo Nordisk, Salix, and Sanofi and as a consultant on medical advisory boards for Ascensia, Merck, Novo Nordisk, and Sanofi. 
Compliance with Ethics Guidelines. This article is based on previously conducted studies and does not contain any studies with human participants or animals performed by any of the authors.

Data Availability. Data sharing is not applicable to this article as no datasets were generated or analyzed during the current study.

Open Access. This article is distributed under the terms of the Creative Commons Attribution-NonCommercial 4.0 International License (http://creativecommons.org/licenses/ by-nc/4.0/), which permits any noncommercial use, distribution, and reproduction in any medium, provided you give appropriate credit to the original author(s) and the source, provide a link to the Creative Commons license, and indicate if changes were made.

\section{REFERENCES}

1. DeFronzo RA, Ferrannini E, Groop L, Henry RR, Herman WH, Holst JJ, et al. Type 2 diabetes mellitus. Nat Rev Dis Primers. 2015;1:15019.

2. Wanner C. EMPA-REG OUTCOME: the nephrologist's point of view. Am J Cardiol. 2017;120:S59-67.

3. Ducat L, Philipson LH, Anderson BJ. The mental health comorbidities of diabetes. JAMA. 2014;312:691-2.

4. Feng X, Astell-Burt T. Impact of a type 2 diabetes diagnosis on mental health, quality of life, and social contacts: a longitudinal study. BMJ Open Diabetes Res Care. 2017;5:e000198.

5. Gonzalez JS, Safren SA, Cagliero E, Wexler DJ, Delahanty L, Wittenberg E, et al. Depression, selfcare, and medication adherence in type 2 diabetes: relationships across the full range of symptom severity. Diabetes Care. 2007;30:2222-7.

6. Marrero D, Pan Q, Barrett-Connor E, de Groot M, Zhang P, Percy C, et al. Impact of diagnosis of diabetes on health-related quality of life among high risk individuals: the diabetes prevention program outcomes study. Qual Life Res. 2014;23:75-88.

7. DeFronzo RA, Eldor R, Abdul-Ghani M. Pathophysiologic approach to therapy in patients with newly diagnosed type 2 diabetes. Diabetes Care. 2013;36(Suppl 2):S127-38.

8. Thrasher J. Pharmacologic management of type 2 diabetes mellitus: available therapies. Am J Med. 2017;130:S4-17.

9. Abdul-Ghani MA, DeFronzo RA. Inhibition of renal glucose reabsorption: a novel strategy for achieving glucose control in type 2 diabetes mellitus. Endocr Pract. 2008;14:782-90.

10. DeFronzo RA, Davidson JA, Del Prato S. The role of the kidneys in glucose homeostasis: a new path towards normalizing glycaemia. Diabetes Obes Metab. 2012;14:5-14.

11. Rahmoune H, Thompson PW, Ward JM, Smith CD, Hong G, Brown J. Glucose transporters in human renal proximal tubular cells isolated from the urine of patients with non-insulin-dependent diabetes. Diabetes. 2005;54:3427-34.

12. DeFronzo RA, Norton L, Abdul-Ghani M. Renal, metabolic and cardiovascular considerations of SGLT2 inhibition. Nat Rev Nephrol. 2017;13:11-26.

13. Abdul-Ghani MA, DeFronzo RA, Norton L. Novel hypothesis to explain why SGLT2 inhibitors inhibit only $30-50 \%$ of filtered glucose load in humans. Diabetes. 2013;62:3324-8.

14. Vallon V, Thomson SC. Targeting renal glucose reabsorption to treat hyperglycaemia: the pleiotropic effects of SGLT2 inhibition. Diabetologia. 2017;60:215-25.

15. Zinman B, Wanner C, Lachin JM, Fitchett D, Bluhmki E, Hantel S, et al. Empagliflozin, cardiovascular outcomes, and mortality in type 2 diabetes. N Engl J Med. 2015;373:2117-28.

16. Wanner C, Inzucchi SE, Lachin JM, Fitchett D, von Eynatten M, Mattheus M, et al. Empagliflozin and progression of kidney disease in type 2 diabetes. N Engl J Med. 2016;375:323-34.

17. Neal B, Perkovic V, Mahaffey KW, de Zeeuw D, Fulcher G, Erondu N, et al. Canagliflozin and cardiovascular and renal events in type 2 diabetes. N Engl J Med. 2017;377:644-57.

18. Wiviott SD, Raz I, Bonaca MP, Mosenzon O, Kato ET, Cahn A, et al. Dapagliflozin and cardiovascular outcomes in type 2 diabetes. $\mathrm{N}$ Engl J Med. 2018;380:347-57.

19. American Diabetes Association. 9. Pharmacologic approaches to glycemic treatment: standards of medical care in diabetes-2019. Diabetes Care. 2019;42:S90-102. 
20. Davies MJ, D'Alessio DA, Fradkin J, Kernan WN, Mathieu C, Mingrone G, Management of hyperglycemia in type 2 diabetes, et al. A consensus report by the American Diabetes Association (ADA) and the European Association for the Study of Diabetes (EASD). Diabetes Care. 2018;2018(41):2669-701.

21. Garber AJ, Abrahamson MJ, Barzilay JI, Blonde L, Bloomgarden ZT, Bush MA, et al. Consensus statement by the American Association of Clinical Endocrinologists and American College of Endocrinology on the comprehensive type 2 diabetes management algorithm-2019 executive summary. Endocr Pract. 2019;25:69-100.

22. Mazidi M, Rezaie P, Gao HK, Kengne AP. Effect of sodium-glucose cotransport- 2 inhibitors on blood pressure in people with type 2 diabetes mellitus: a systematic review and meta-analysis of 43 randomized control trials with 22,528 patients. J Am Heart Assoc. 2017;6:e004007.

23. Liu XY, Zhang N, Chen R, Zhao JG, Yu P. Efficacy and safety of sodium-glucose cotransporter 2 inhibitors in type 2 diabetes: a meta-analysis of randomized controlled trials for 1 to 2 years. J Diabetes Complicat. 2015;29:1295-303.

24. Zaccardi F, Webb DR, Htike ZZ, Youssef D, Khunti K, Davies MJ. Efficacy and safety of sodium-glucose co-transporter- 2 inhibitors in type 2 diabetes mellitus: systematic review and network meta-analysis. Diabetes Obes Metab. 2016;18:783-94.

25. Fitchett D, Zinman B, Wanner C, Lachin JM, Hantel S, Salsali A, et al. Heart failure outcomes with empagliflozin in patients with type 2 diabetes at high cardiovascular risk: results of the EMPA-REG OUTCOME $^{\circledR}$ trial. Eur Heart J. 2016;37:1526-34.

26. Rådholm K, Figtree G, Perkovic V, Solomon SD, Mahaffey KW, de Zeeuw D, et al. Canagliflozin and heart failure in type 2 diabetes mellitus: results from the CANVAS program. Circulation. 2018;138: 458-68.

27. Atac BS. Study design, population, and key outcomes of DECLARE-TIMI 58 compared with other cardiovascular outcomes trials for sodium-glucose cotransporter-2 inhibitors. J Fam Pract. 2019;68(Suppl):1.

28. Furtado RHM, Bonaca MP, Raz I, Zelniker TA, Mosenzon O, Cahn A, et al. Dapagliflozin and cardiovascular outcomes in patients with type 2 diabetes and prior myocardial infarction: a sub-analysis from DECLARE TIMI-58 trial. Circulation. 2019;139:2516-27.

29. Kato ET, Silverman MG, Mosenzon O, Zelniker TA, Cahn A, Furtado RHM, et al. Effect of dapagliflozin on heart failure and mortality in type 2 diabetes mellitus. Circulation. 2019;139:2528-36.

30. Zelniker TA, Wiviott SD, Raz I, Im K, Goodrich EL, Bonaca MP, et al. SGLT2 inhibitors for primary and secondary prevention of cardiovascular and renal outcomes in type 2 diabetes: a systematic review and meta-analysis of cardiovascular outcome trials. Lancet. 2019;393:31-9.

31. Zelniker TA, Wiviott SD, Raz I, Im K, Goodrich EL, Furtado RHM, et al. Comparison of the effects of glucagon-like peptide receptor agonists and sodium-glucose cotransporter 2 inhibitors for prevention of major adverse cardiovascular and renal outcomes in type 2 diabetes mellitus. Circulation. 2019;139:2022-31.

32. Kosiborod M, Cavender MA, Fu AZ, Wilding JP, Khunti K, Holl RW, et al. Lower risk of heart failure and death in patients initiated on sodium-glucose cotransporter-2 inhibitors versus other glucoselowering drugs: the CVD-REAL Study (comparative effectiveness of cardiovascular outcomes in new users of sodium-glucose cotransporter-2 inhibitors). Circulation. 2017;136:249-59.

33. Birkeland KI, Jorgensen ME, Carstensen B, Persson F, Gulseth HL, Thuresson M, et al. Cardiovascular mortality and morbidity in patients with type 2 diabetes following initiation of sodium-glucose cotransporter-2 inhibitors versus other glucose-lowering drugs (CVD-REAL Nordic): a multinational observational analysis. Lancet Diabetes Endocrinol. 2017;5:709-17.

34. Persson F, Nystrom T, Jorgensen ME, Carstensen B, Gulseth HL, Thuresson M, et al. Dapagliflozin is associated with lower risk of cardiovascular events and all-cause mortality in people with type 2 diabetes (CVD-REAL Nordic) when compared with dipeptidyl peptidase- 4 inhibitor therapy: a multinational observational study. Diabetes Obes Metab. 2018;20:344-51.

35. Cavender MA, Norhammar A, Birkeland KI, Jorgensen ME, Wilding JP, Khunti $\mathrm{K}$, et al. SGLT-2 inhibitors and cardiovascular risk: an analysis of CVD-REAL. J Am Coll Cardiol. 2018;71:2497-506.

36. Kosiborod M, Lam CSP, Kohsaka S, Kim DJ, Karasik A, Shaw J, et al. Cardiovascular events associated with SGLT-2 inhibitors versus other glucose-lowering drugs: the CVD-REAL 2 Study. J Am Coll Cardiol. 2018;71:2628-39.

37. Gautam S, Agiro A, Barron J, Power T, Weisman H, White J. Heart failure hospitalization risk associated with use of two classes of oral antidiabetic medications: an observational, real-world analysis. Cardiovasc Diabetol. 2017;16:93. 
38. Kim YG, Han SJ, Kim DJ, Lee KW, Kim HJ. Association between sodium glucose co-transporter 2 inhibitors and a reduced risk of heart failure in patients with type 2 diabetes mellitus: a real-world nationwide population-based cohort study. Cardiovasc Diabetol. 2018;17:91.

39. Norhammar A, Bodegard J, Nystrom T, Thuresson M, Nathanson D, Eriksson JW. Dapagliflozin and cardiovascular mortality and disease outcomes in a population with type 2 diabetes similar to that of the DECLARE-TIMI 58 trial: a nationwide observational study. Diabetes Obes Metab. 2019;21:1136-45.

40. Patorno E, Goldfine AB, Schneeweiss S, Everett BM, Glynn RJ, Liu J, et al. Cardiovascular outcomes associated with canagliflozin versus other non-gliflozin antidiabetic drugs: population based cohort study. BMJ. 2018;360:k119.

41. Patorno E, Pawar A, Franklin JM, Najafzadeh M, Deruaz-Luyet A, Brodovicz KG, et al. Empagliflozin and the risk of heart failure hospitalization in routine clinical care: a first analysis from the empagliflozin comparative effectiveness and safety (EMPRISE) study. Circulation. 2019;139:2822-30.

42. Heerspink HJ, Perkins BA, Fitchett DH, Husain M, Cherney DZ. Sodium glucose cotransporter 2 inhibitors in the treatment of diabetes mellitus: cardiovascular and kidney effects, potential mechanisms, and clinical applications. Circulation. 2016;134:752-72.

43. Verma S, McMurray JJV. SGLT2 inhibitors and mechanisms of cardiovascular benefit: a state-ofthe-art review. Diabetologia. 2018;61:2108-17.

44. Ferrannini E, Mark M, Mayoux E. CV protection in the EMPA-REG OUTCOME trial: a "thrifty substrate" hypothesis. Diabetes Care. 2016;39:1108-14.

45. Mudaliar S, Alloju S, Henry RR. Can a shift in fuel energetics explain the beneficial cardiorenal outcomes in the EMPA-REG OUTCOME study? A unifying hypothesis. Diabetes Care. 2016;39:1115-22.

46. Chilton R, Tikkanen I, Cannon CP, Crowe S, Woerle HJ, Broedl UC, et al. Effects of empagliflozin on blood pressure and markers of arterial stiffness and vascular resistance in patients with type 2 diabetes. Diabetes Obes Metab. 2015;17:1180-93.

47. Chilton RJ, Gullestad L, Fitchett D, Inzucchi SE, Mattheus M, Woerle HJ, et al. Empagliflozin reduces markers of arterial stiffness, vascular resistance and cardiac workload in EMPA-REG OUTCOME. Circulation. 2016;134(25):A13520.

48. Ott C, Jumar A, Striepe K, Friedrich S, Karg MV, Bramlage $\mathrm{P}$, et al. A randomised study of the impact of the SGLT2 inhibitor dapagliflozin on microvascular and macrovascular circulation. Cardiovasc Diabetol. 2017;16:26.

49. Pfeifer M, Townsend RR, Davies MJ, Vijapurkar U, Ren J. Effects of canagliflozin, a sodium glucose cotransporter 2 inhibitor, on blood pressure and markers of arterial stiffness in patients with type 2 diabetes mellitus: a post hoc analysis. Cardiovasc Diabetol. 2017;16:29.

50. Solini A, Giannini L, Seghieri M, Vitolo E, Taddei S, Ghiadoni L, et al. Dapagliflozin acutely improves endothelial dysfunction, reduces aortic stiffness and renal resistive index in type 2 diabetic patients: a pilot study. Cardiovasc Diabetol. 2017;16:138.

51. Townsend RR, Machin I, Ren J, Trujillo A, Kawaguchi M, Vijapurkar U, et al. Reductions in mean 24-hour ambulatory blood pressure after 6-week treatment with canagliflozin in patients with type 2 diabetes mellitus and hypertension. J Clin Hypertens. 2016;18:43-52.

52. Zinman B, Lachin JM, Inzucchi SE. Correspondence: empagliflozin, cardiovascular outcomes, and mortality in type 2 diabetes. $\mathrm{N}$ Engl J Med. 2016;374:1094.

53. Daniele G, Xiong J, Solis-Herrera C, Merovci A, Eldor R, Tripathy D, et al. Dapagliflozin enhances fat oxidation and ketone production in patients with type 2 diabetes. Diabetes Care. 2016;39:2036-41.

54. Ferrannini E, Muscelli E, Frascerra S, Baldi S, Mari A, Heise $\mathrm{T}$, et al. Metabolic response to sodium-glucose cotransporter 2 inhibition in type 2 diabetic patients. J Clin Invest. 2014;124:499-508.

55. Staels B. Cardiovascular protection by sodium glucose cotransporter 2 inhibitors: potential mechanisms. Am J Med. 2017;130:S30-9.

56. Kusaka H, Koibuchi N, Hasegawa Y, Ogawa H, KimMitsuyama S. Empagliflozin lessened cardiac injury and reduced visceral adipocyte hypertrophy in prediabetic rats with metabolic syndrome. Cardiovasc Diabetol. 2016;15:157.

57. Lin B, Koibuchi N, Hasegawa Y, Sueta D, Toyama K, Uekawa K, et al. Glycemic control with empagliflozin, a novel selective SGLT2 inhibitor, ameliorates cardiovascular injury and cognitive dysfunction in obese and type 2 diabetic mice. Cardiovasc Diabetol. 2014;13:148.

58. Cannon CP, McGuire DK, Pratley R, Dagogo-Jack S, Mancuso J, Huyck S, et al. Design and baseline characteristics of the eValuation of ERTugliflozin effIcacy and Safety CardioVascular outcomes trial (VERTIS-CV). Am Heart J. 2018;206:11-23. 
59. Perkovic V, de Zeeuw D, Mahaffey KW, Fulcher G, Erondu N, Shaw W, et al. Canagliflozin and renal outcomes in type 2 diabetes: results from the CANVAS program randomised clinical trials. Lancet Diabetes Endocrinol. 2018;6:691-704.

60. Mosenzon O, Wiviott SD, Cahn A, Rozenberg A, Yanuv I, Goodrich EL, et al. Effects of dapagliflozin on development and progression of kidney disease in patients with type 2 diabetes: an analysis from the DECLARE-TIMI 58 randomised trial. Lancet Diabetes Endocrinol. 2019;7:606-17.

61. Raz I, Wiviott SD, Yanuv I, Rozenberg A, Zelniker TA, Cahn A, et al. Effects of dapagliflozin on the urinary albumin-to-creatinine ratio in patients with type 2 diabetes: a predefined analysis from the DECLARE-TIMI 58 randomised, placebo-controlled trial. Diabetes. 2019;68(Suppl 1):244-OR.

62. Wang C, Zhou Y, Kong Z, Wang X, Lv W, Geng Z, et al. The renoprotective effects of sodium-glucose cotransporter 2 inhibitors versus placebo in patients with type 2 diabetes with or without prevalent kidney disease: a systematic review and meta-analysis. Diabetes Obes Metab. 2019;21:1018-26.

63. Perkovic V, Jardine MJ, Neal B, Bompoint S, Heerspink HJL, Charytan DM, et al. Canagliflozin and renal outcomes in type 2 diabetes and nephropathy. N Engl J Med. 2019;380:2295-306.

64. Pollock C, Stefánsson B, Reyner D, Rossing P, Sjöström CD, Wheeler DC, et al. Albuminuria-lowering effect of dapagliflozin alone and in combination with saxagliptin and effect of dapagliflozin and saxagliptin on glycaemic control in patients with type 2 diabetes and chronic kidney disease (DELIGHT): a randomised, double-blind, placebocontrolled trial. Lancet Diabetes Endocrinol. 2019;7:429-41.

65. Alicic RZ, Johnson EJ, Tuttle KR. SGLT2 inhibition for the prevention and treatment of diabetic kidney disease: a review. Am J Kidney Dis. 2018;72:267-77.

66. Packer M. Activation and inhibition of sodium-hydrogen exchanger is a mechanism that links the pathophysiology and treatment of diabetes mellitus with that of heart failure. Circulation. 2017;136:1548-59.

67. Heerspink HJ, Desai M, Jardine M, Balis D, Meininger G, Perkovic V. Canagliflozin slows progression of renal function decline independently of glycemic effects. J Am Soc Nephrol. 2017;28:368-75.

68. Bankir L, Roussel R, Bouby N. Protein- and diabetesinduced glomerular hyperfiltration: role of glucagon, vasopressin, and urea. Am J Physiol Renal Physiol. 2015;309:F2-23.
69. Pereira MJ, Eriksson JW. Emerging role of SGLT-2 inhibitors for the treatment of obesity. Drugs. 2019;79:219-30.

70. Abdul-Ghani MA, Norton L, Defronzo RA. Role of sodium-glucose cotransporter 2 (SGLT 2) inhibitors in the treatment of type 2 diabetes. Endocr Rev. 2011;32:515-31.

71. Scheen AJ. Pharmacodynamics, efficacy and safety of sodium-glucose co-transporter type 2 (SGLT2) inhibitors for the treatment of type 2 diabetes mellitus. Drugs. 2015;75:33-59.

72. Vasilakou D, Karagiannis T, Athanasiadou E, Mainou M, Liakos A, Bekiari E, et al. Sodium-glucose cotransporter 2 inhibitors for type 2 diabetes: a systematic review and meta-analysis. Ann Intern Med. 2013;159:262-74.

73. Ferrannini G, Hach T, Crowe S, Sanghvi A, Hall KD, Ferrannini E. Energy balance after sodium-glucose cotransporter 2 inhibition. Diabetes Care. 2015;38:1730-5.

74. Bolinder J, Ljunggren O, Johansson L, Wilding J, Langkilde AM, Sjostrom CD, et al. Dapagliflozin maintains glycaemic control while reducing weight and body fat mass over 2 years in patients with type 2 diabetes mellitus inadequately controlled on metformin. Diabetes Obes Metab. 2014;16:159-69.

75. Cefalu WT, Leiter LA, Yoon KH, Arias P, Niskanen L, Xie J, et al. Efficacy and safety of canagliflozin versus glimepiride in patients with type 2 diabetes inadequately controlled with metformin (CANTATA-SU): 52 week results from a randomised, double-blind, phase 3 non-inferiority trial. Lancet. 2013;382:941-50.

76. Thomas MC, Cherney DZI. The actions of SGLT2 inhibitors on metabolism, renal function and blood pressure. Diabetologia. 2018;61:2098-107.

77. Rajasekeran H, Lytvyn Y, Cherney DZ. Sodium-glucose cotransporter 2 inhibition and cardiovascular risk reduction in patients with type 2 diabetes: the emerging role of natriuresis. Kidney Int. 2016;89:524-6.

78. Merovci A, Mari A, Solis-Herrera C, Xiong J, Daniele G, Chavez-Velazquez A, et al. Dapagliflozin lowers plasma glucose concentration and improves betacell function. J Clin Endocrinol Metab. 2015;100:1927-32.

79. Merovci A, Solis-Herrera C, Daniele G, Eldor R, Fiorentino TV, Tripathy D, et al. Dapagliflozin improves muscle insulin sensitivity but enhances endogenous glucose production. J Clin Invest. 2014;124:509-14. 
80. Hayashi T, Fukui T, Nakanishi N, Yamamoto S, Tomoyasu M, Osamura A, et al. Dapagliflozin decreases small dense low-density lipoprotein-cholesterol and increases high-density lipoprotein 2-cholesterol in patients with type 2 diabetes: comparison with sitagliptin. Cardiovasc Diabetol. 2017; 16:8.

81. Kuchay MS, Krishan S, Mishra SK, Farooqui KJ, Singh MK, Wasir JS, et al. Effect of empagliflozin on liver fat in patients with type 2 diabetes and nonalcoholic fatty liver disease: a randomized controlled trial (E-LIFT trial). Diabetes Care. 2018;41:1801-8.

82. Latva-Rasku A, Honka MJ, Kullberg J, Mononen N, Lehtimaki T, Saltevo J, et al. The SGLT2 inhibitor dapagliflozin reduces liver fat but does not affect tissue insulin sensitivity: a randomized, doubleblind, placebo controlled study with 8-week treatment in type 2 diabetes patients. Diabetes Care. 2019;42:931-7.

83. Zhao D, Liu H, Dong P. Empagliflozin reduces blood pressure and uric acid in patients with type 2 diabetes mellitus: a systematic review and meta-analysis. J Hum Hypertens. 2019;33:327-39.

84. Davies MJ, Trujillo A, Vijapurkar U, Damaraju CV, Meininger G. Effect of canagliflozin on serum uric acid in patients with type 2 diabetes mellitus. Diabetes Obes Metab. 2015;17:426-9.

85. Kohan DE, Fioretto P, Tang W, List JF. Long-term study of patients with type 2 diabetes and moderate renal impairment shows that dapagliflozin reduces weight and blood pressure but does not improve glycemic control. Kidney Int. 2014;85:962-71.

86. Musso G, Gambino R, Cassader M, Pagano G. A novel approach to control hyperglycemia in type 2 diabetes: sodium glucose co-transport (SGLT) inhibitors: systematic review and meta-analysis of randomized trials. Ann Med. 2012;44:375-93.

87. Brown AJM, Lang C, McCrimmon R, Struthers A. Does dapagliflozin regress left ventricular hypertrophy in patients with type 2 diabetes? A prospective, double-blind, randomised, placebocontrolled study. BMC Cardiovasc Disord. 2017;17:229.

88. Natali A, Nesti L, Fabiani I, Calogero E, Di Bello V. Impact of empagliflozin on subclinical left ventricular dysfunctions and on the mechanisms involved in myocardial disease progression in type 2 diabetes: rationale and design of the EMPA-HEART trial. Cardiovasc Diabetol. 2017;16:130.

89. Singh JS, Fathi A, Vickneson K, Mordi I, Mohan M, Houston JG, et al. Research into the effect of SGLT2 inhibition on left ventricular remodelling in patients with heart failure and diabetes mellitus (REFORM) trial rationale and design. Cardiovasc Diabetol. 2016;15:97.

90. Cherney DZ, Perkins BA, Soleymanlou N, Har R, Fagan N, Johansen OE, et al. The effect of empagliflozin on arterial stiffness and heart rate variability in subjects with uncomplicated type 1 diabetes mellitus. Cardiovasc Diabetol. 2014;13:28.

91. Lee TM, Chang NC, Lin SZ. Dapagliflozin, a selective SGLT2 inhibitor, attenuated cardiac fibrosis by regulating the macrophage polarization via STAT3 signaling in infarcted rat hearts. Free Radic Biol Med. 2017;104:298-310.

92. Byrne NJ, Parajuli N, Levasseur JL, Boisvenue J, Beker DL, Masson G, et al. Empagliflozin prevents worsening of cardiac function in an experimental model of pressure overload-induced heart failure. JACC Basic Transl Sci. 2017;2:347-54.

93. Verma S, Mazer CD, Yan AT, Mason T, Slabiak A, Bello OO, et al. EMPA-HEART Cardiolink-6 trial: a randomized trial evaluating the effect of empagliflozin on left ventricular structure, function and biomarkers in people with type 2 diabetes (T2D) and coronary heart disease [abstract]. Circulation. 2018;138(25):A19332.

94. Storgaard H, Gluud LL, Bennett C, Grondahl MF, Christensen MB, Knop FK, et al. Benefits and harms of sodium-glucose co-transporter 2 inhibitors in patients with type 2 diabetes: a systematic review and meta-analysis. PLoS One. 2016;11:e0166125.

95. Dave CV, Schneeweiss S, Kim D, Fralick M, Tong A, Patorno E. Sodium-glucose cotransporter-2 inhibitors and the risk for severe urinary tract infections: a population-based cohort study. Ann Intern Med. 2019. https://doi.org/10.7326/m18-3136 (published online ahead of print July 30, 2019).

96. Peters AL, Buschur EO, Buse JB, Cohan P, Diner JC, Hirsch IB. Euglycemic diabetic ketoacidosis: a potential complication of treatment with sodium-glucose cotransporter 2 inhibition. Diabetes Care. 2015;38:1687-93.

97. Invokana (canagliflozin) [package insert]. Titusville: Janssen Pharmaceuticals, Inc.; 2018. http://www. janssenlabels.com/package-insert/product-monograph/prescribing-information/INVOKANA-pi.pdf. Accessed 21 Aug 2019.

98. Farxiga (dapagliflozin) [package insert]. Wilmington: AstraZeneca Pharmaceuticals LP; 2019. https:// www.accessdata.fda.gov/drugsatfda_docs/label/2017/ 202293s012lbl.pdf. Accessed 21 Aug 2019.

99. Jardiance (empagliflozin) [package insert]. Ridgefield: Boehringer Ingelheim Pharmaceuticals, Inc.; 
2018. https://www.accessdata.fda.gov/drugsatfda docs/label/2016/204629s008lbl.pdf. Accessed 21 Aug 2019.

100. Steglatro (ertugliflozin) [package insert]. Whitehouse Station: Merck and Co., Inc.; 2018. https:// www.accessdata.fda.gov/drugsatfda_docs/label/2017/ 209803s000lbl.pdf. Accessed 21 Aug 2019.

101. Cahn A, Melzer-Cohen C, Pollack R, Chodick G, Shalev V. Acute renal outcomes with sodium-glucose co-transporter-2 inhibitors: real-world data analysis. Diabetes Obes Metab. 2019;21:340-8.

102. Ryan PB, Buse JB, Schuemie MJ, DeFalco F, Yuan Z, Stang PE, et al. Comparative effectiveness of canagliflozin, SGLT2 inhibitors and non-SGLT2 inhibitors on the risk of hospitalization for heart failure and amputation in patients with type 2 diabetes mellitus: a real-world meta-analysis of 4 observational databases (OBSERVE-4D). Diabetes Obes Metab. 2018;20:2585-97.

103. Inzucchi SE, Iliev H, Pfarr E, Zinman B. Empagliflozin and assessment of lower-limb amputations in the EMPA-REG OUTCOME trial. Diabetes Care. 2018;41:e4-5.
104. Toulis KA, Bilezikian JP, Thomas GN, Hanif W, Kotsa K, Thayakaran R, et al. Initiation of dapagliflozin and treatment-emergent fractures. Diabetes Obes Metab. 2018;20:1070-4.

105. US Food and Drug Administration. FDA drug safety communications: FDA warns about rare occurrences of a serious infection of the genital area with SGLT2 inhibitors for diabetes. 2018. http://www.fda.gov/ Drugs/DrugSafety/ucm617360.htm. Accessed 19 Feb 2019.

106. Bersoff-Matcha SJ, Chamberlain C, Cao C, Kortepeter $\mathrm{C}$, Chong WH. Fournier gangrene associated with sodium-glucose cotransporter-2 inhibitors: a review of spontaneous postmarketing cases. Ann Intern Med. 2019;170:764-9.

107. Ptaszynska A, Cohen SM, Messing EM, Reilly TP, Johnsson E, Johnsson K. Assessing bladder cancer risk in type 2 diabetes clinical trials: the dapagliflozin drug development program as a 'case study'. Diabetes Ther. 2015;6:357-75.

108. Kohler S, Lee J, George JT, Inzucchi SE, Zinman B. Bladder cancer in the EMPA-REG OUTCOME trial. Diabetologia. 2017;60:2534-5. 